\title{
The Solid-State and Solution-State Reassigned Structures of Tagitinin A, a 3,10-Epoxy- Germacrolide from Tithonia diversifolia, and the Interconversion of 3,10-Epoxy-Germacrolide Conformational Families via a Ring-Atom Flip Mechanism
}

\author{
Robert Glaser ${ }^{*, \#, a}$, Abraham García ${ }^{b}$, María Isabel Chávez ${ }^{b}$ and Guillermo Delgado*,\#,b \\ ${ }^{a}$ Department of Chemistry, Ben-Gurion University of the Negev, Beer-Sheva 84105, Israel \\ ${ }^{b}$ Instituto de Química, Universidad Nacional Autónoma de México, Circuito Exterior, Ciudad Universitaria, \\ Coyoacán, 04510 México D. F., México
}

\begin{abstract}
Tagitinina A(2), uma 3,10-epoxi-germacrolida-6,7-trans-lactona conhecida e isolada de Tithonia diversifolia foi estudada através de difração de raios-X de monocristal. Verificou-se que a mesma apresenta a configuração relativa $1 \beta, 4 \alpha, 6 \alpha, 7 \beta, 8 \beta$ que difere da orientação $1 \alpha$ em $\mathrm{C}(1)$ proposta originalmente na literatura e que foi determinada pelo método de Horeau. Análise do espectro de ${ }^{1} \mathrm{H}-$ RMN de 2 em solução de $d 6$-acetona mostra que a molécula mantém a conformação twist-chair-boat (TCB) observada cristalograficamente para o anel de 9 membros. As conformações twist-chairboat/skew-chair-boat do tipo 3 para anéis de 9 membros saturados e insaturados dentro das 3,10epoxi-germacrolídas podem ser convertidas à conformação skew-chair-chair (SCC) através de mecanismo de inversão de C(9) do anel. Como resultado dessa mudança conformacional, a orientação de $\mathrm{C}(1)$ e de $\mathrm{C}(8)$ da unidade oxicarbonila são transformados de diequatorial para diaxial. A estereoquímica relatada para lactonas do tipo 3,10-epoxi-germacrolida e resultados de modelagem utilizando-se DFT B3LYP/6-31g(d) indicam que os átomos C(1) tetraédricos estabilizam conformações TCB/SCB do tipo 3 enquanto que aqueles com geometria trigonal estabilizam a conformação SCC.
\end{abstract}

Tagitinin A (2), a known 3,10-epoxy-germacrolide-6,7-trans-lactone isolated from Tithonia diversifolia, was investigated by single crystal X-ray diffraction analysis. It was found to have a $1 \beta, 4 \alpha, 6 \alpha, 7 \beta, 8 \beta$ relative configuration which differed at $\mathrm{C}(1)$ from the $1 \alpha$-orientation originally reported in the literature which was determined by Horeau's Rule. Analysis of the 1H NMR spectrum of 2 shows the molecule to maintain its crystallographically observed twist-chair-boat (TCB) ninemembered ring conformation in acetone- $d 6$ solution. The twist-chair-boat/skew-chair-boat type 3 conformations of saturated/unsaturated nine-membered rings within 3,10-epoxy-germacrolides can be interconverted to the skew-chair-chair (SCC) conformation by means of a $\mathrm{C}(9)$ ring atom flip mechanism. As a result of this conformational change, the orientation of the $C(1)$ atom and the $C(8)$ oxycarbonyl moiety are transformed from diequatorial to diaxial. The reported stereochemistry of 3,10-epoxy-germacrolide lactone structures, and the DFT B3LYP/6-31g(d) modeling findings in this work indicate that tetrahedral C(1) atoms stabilize the TCB/SCB type 3 conformations, while their trigonal counterparts stabilize the SCC conformation.

Keywords: tagitinin A, Horeau's rule, conformational interconversion, molecular modeling

\section{Introduction}

Horeau's rule ${ }^{1}$ to determine the absolute configuration of chirotopic stereogenic secondary alcohols is considered

\footnotetext{
* e-mail: rglaser@bgumail.bgu.ac.il; delgado@servidor.unam.mx \# Dedicated to Prof. Kurt Mislow on the occassion of his 80th birthday and to Prof. Alfonso Romo de Vivar, for his 50 years of research at the Instituto de Química, UNAM.

".... III, verse 12 .
}

to be a well-known and proven method, ${ }^{2}$ and has been reviewed by Brewster ${ }^{3}$ and Horeau. ${ }^{4}$ It was used to determine the $(R / S)$-absolute configuration and subsequent $\alpha, \beta$-orientation ${ }^{5,6}$ of secondary hydroxyl groups in 3,10 epoxy germacrolide 6,7-trans-lactone sesquiterpene natural products whose 3,10-oxiranyl oxygen affords a $\mathrm{C}(3)-\mathrm{O}-\mathrm{C}(10)$ - fragment common to either a $3(2 \mathrm{H})$ furanone [e.g. zexbrevin $\left.{ }^{7}(\mathbf{1})\right]$ or to a cis-fused tetrahydrofurano moiety [e.g. tagitinin $\mathrm{A}^{8}(2)$ ] (both drawn with $(6 R, 7 S)$-stereochemistry). The skeletons of these 
compounds are based upon 1-isopropyl-4,8dimethylcyclodecane (germacrane). ${ }^{9}$ In this method, a chiral secondary-alcohol will react faster with one of the enantiotopic $\mathrm{C}_{2} \mathrm{H}_{5} \mathrm{C} * \mathrm{H}(\mathrm{Ph}) \mathrm{C}(=\mathrm{O}) \mathrm{O}$ - carbonyl groups in excess optically inactive 2-phenylbutyric anhydride [a mixture of $d, l$ and meso-diastereomers] than with its enantiotopic counterpart in a type of kinetic resolution. Isolation of the excess unreacted 2-phenylbutyric acid enables correlation of its sign of optical rotation with the spatial disposition of small, medium, and large local environments around the secondary carbinol carbon.

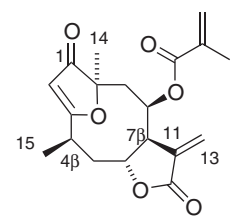

1

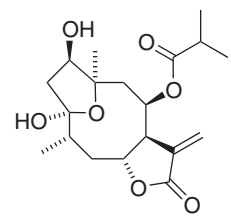

2

$$
[\mathrm{C}(9)] \mathrm{M} \frac{\stackrel{\mathrm{H}}{\overline{\mathrm{O}}}}{\mathrm{O}} \mathrm{L}[\mathrm{C}(7)]
$$

4
Zexbrevin (1) has been isolated from the Zexmenia brevifolia plant, and its structure and stereochemistry were reported by Romo de Vivar et al. ${ }^{7}$ It was converted in a number of steps to 8-desmethylacryl-hexahydroxyzexbrevin [originally drawn with $4 \alpha, 11 \alpha$-dimethyl groups, but now known by X-ray diffraction analysis ${ }^{10}$ to be $4 \beta, 11 \beta$ and subsequently illustrated as 3 ] and the stereochemistry of the free 8-OH was ascertained according to Horeau's procedure as follows. The excess recovered (-)- $\alpha$-phenylbutyric acid was reported to exhibit $[\alpha]_{\mathrm{D}}{ }^{27}-12^{\circ}$, representing an optical yield of $53.3 \%$. According to the rule, the small, medium, and large local environments around $\mathrm{C}(8)$ are represented as in $\mathbf{4}$, and the absolute configuration was assigned as $(8 S)$. Using a $(6 R, 7 S)-6,7$-trans-lactone skeleton and the $(8 S)$ result, the authors ${ }^{7}$ reported an $\alpha$-orientation for the 8-hydroxyl group. However, the X-ray crystallographically determined structures of tetrahydrozexbrevin (5) ${ }^{10}$ and $9 \alpha$ acetoxyzexbrevin, ${ }^{11}$ and phototetrahydrozexbrevin $\mathrm{A}^{12,13}$ were later reported, and the orientation of the 8 isobutyryloxy moiety was then found to be ' $\beta$ ' for all three compounds. Horeau's rule failed to predict the correct $\alpha$-orientation in this case.
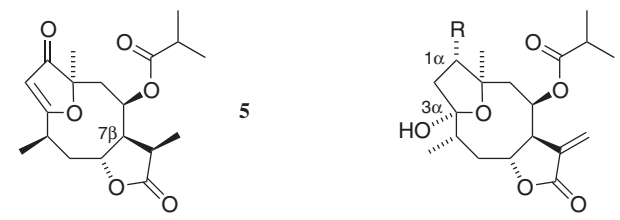

6a $\mathrm{R}=\mathrm{H}$ 6b $\mathrm{R}=\mathrm{OH}$
Tagitinin A (2) was originally isolated by Pal et al. ${ }^{14}$ from Tithonia diversifolia. Due to its similarity to tirotundin (6a) and its similar chemical behavior, Pal et al. ${ }^{14}$ proposed structure $\mathbf{6 b}$ without specification of stereochemistry at $\mathrm{C}(1)$, $\mathrm{C}(4)$, and C(8). Herz and de Jong ${ }^{8}$ undertook a more extensive study of tagitinin A and related compounds. They determined the stereochemistry of the 4-methyl and 8 -isobutyryloxy moieties to be $4 \alpha$ and $8 \beta$, respectively, and reported ${ }^{1} \mathrm{H}$ and ${ }^{13} \mathrm{C}$ NMR chemical shifts [measured at 270 and $67.9 \mathrm{MHz}$, respectively, $\mathrm{CDCl}_{3}$ ], plus some of the $J_{\mathrm{HH}}$ coupling constants. ${ }^{8}$ They also utilized Horeau's method to determine the stereochemistry of the chirotopic stereogenic secondary hydroxyl fragment at $\mathrm{C}(1)$, and found it to be $(1 S) .{ }^{8}$ The excess recovered (-)- $\alpha$-phenylbutyric acid was reported to exhibit $[\alpha]_{\mathrm{D}}{ }^{27}-6.55^{\circ}$ (benzene), representing an optical yield of $41.8 \% .^{8}$ Based upon a $(6 R, 7 S)$-skeleton for 6b, they proposed an $\alpha$-orientation for the 1-hydroxyl group. ${ }^{8}$ Structure $\mathbf{6 b}$ depicts the stereochemistry of tagitinin A as illustrated in the report of Herz et al. ${ }^{8}$ The failure of Horeau's rule with the deacylzexbrevin derivative $\mathbf{3}$ prompted us to reinvestigate the tagitinin A stereochemistry at $\mathrm{C}(1)$. This paper reports the solid-state twist-chair-boat (TCB) conformation of the nine-membered ring in $\mathbf{2}$ (as determined by single crystal X-ray diffraction analysis) and the reassignment of a $\beta$-orientation for the $\mathrm{C}(1)$-hydroxyl. The solution-state stereochemistry (utilizing NMR techniques) is also described herein. Furthermore, the classification of $3(2 \mathrm{H})$-furanone [e.g. 1] or cis-fused tetrahydrofurano [e.g. 2] 3,10-epoxy-germacrolides into respective oxacyclononane skew-chair-chair (SCC) and twist-chair-boat/skew-chair-boat

( $\mathrm{TCB} / \mathrm{SCB}$ ) conformational families, ${ }^{15}$ and their theoretical interconversion via a $\mathrm{C}(9)$ atom-flip mechanism is also discussed herein.

\section{Results and Discussion}

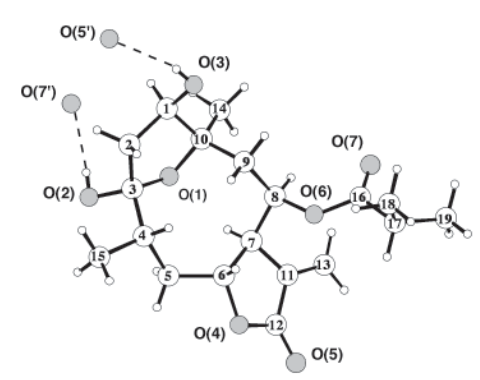

7

Solid-state stereochemistry of tagitinin A

Tagitinin A (2) was isolated from T. diversifolia, and its chemical and physical properties were found to be identical 
to those described in the literature. ${ }^{8} T$. diversifolia (also known as "Mexican arnica") has been used in Mexican traditional medicine to treat inflammatory ailments. Its ethnopharmacology has been discussed recently. ${ }^{16}$ Compound 2 was subjected to X-ray diffraction analysis, but the absolute configuration ${ }^{17}$ of the chiral crystal was unable to be determined. ${ }^{18}$ The resulting molecular structure (depicted as Ball and Stick ${ }^{19}$ model 7) within these crystals showed that the originally proposed $\alpha$-oriented 1-hydroxy group was indeed inverted to a $\beta$-orientation. From now on, model 7 will refer to the solidstate structure of crystalline $\mathbf{2}$. No unusual bond lengths or bond angles were measured. The hydrogens were placed at calculated positions, and refined as riding atoms on their respective attached atom, with the exception of those ligated to $\mathrm{O}(2)$ and $\mathrm{O}(3)$ which were located and refined anisotropically. Intermolecular $\mathrm{H}(\mathrm{O} 2) \cdots \mathrm{O}\left(7^{\prime}\right)$ and $\mathrm{H}(\mathrm{O} 3) \ldots \mathrm{O}\left(5^{\prime}\right)$ hydrogen-bonds are present in the unit-cell, where $\mathrm{O}\left(7^{\prime}\right)$ and $\mathrm{O}\left(5^{\prime}\right)$ are 8-oxycarbonyl and lactonyl carbonyl oxygen atoms related by the respective $[-x+1.5$, $-y, z-0.5]$ and $[-x+0.5,-y+0.5,-z]$ symmetry transformations.

Evidently, within the diastereomeric transition-states of the kinetically controlled Horeau reaction, the "medium" versus "large" bulk or steric volume expressed by a particular sub-unit attached to the chirotopic stereogenic secondary carbinol carbon atom may not always be discernible by inspection of simple models. This may rationalize the failure of Horeau's rule to correctly predict both the 1-hydroxyl orientation in 7 and the 8-hydroxyl disposition in 3. Alternatively, one perhaps could argue that the two experimental findings for 7 [(1S)stereochemistry by Horeau's rule based and $1 \beta$-relative configuration by X-ray crystallography, as well as $(8 S)$ stereochemistry $/ 8 \beta$-relative configuration for 1] are not actually mutually exclusive, but that the germacrolide skeleton simply has the opposite $(6 S, 7 R)$-6,7-trans-lactone stereochemistry since neither the absolute configuration of 7 nor those of the zexbrevin-type compounds (e.g. 3,5) were ever determined by X-ray crystallography. However, this assertion is untenable since numerous $\mathrm{X}$-ray crystallographic determinations of $(6 R, 7 S)$-absolute configuration for other germacrolide 6,7-trans-lactone natural products are listed in the Cambridge Crystallographic Data $\mathrm{Base}^{20}(\mathrm{CCDB})$, and one can assume that the biosynthetic pathways determining chirality are all very similar for this class of compounds. A few of the many recent representative $\mathrm{CCDB}$ examples of germacrolide X-ray crystallographic absolute configuration determinations were arbitrarily chosen..$^{21-24}$ Thus, it is very reasonable that the absolute configuration of the 6,7-trans-lactone fragment in the tagitinin A and zexbrevin 3,10-epoxy-germacrolide skeletons should also be $(6 R, 7 S)$, leaving us with the conclusion that Horeau's rule failed in both cases.

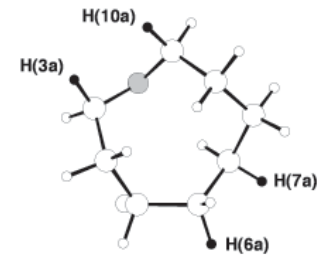

8

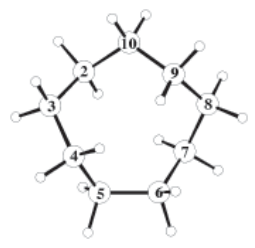

9

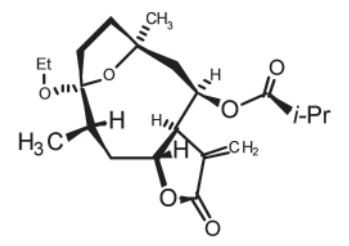

10

The $\mathrm{O}(1)$, and $\mathrm{C}(3-10)$ atoms of 2 define an oxacyclononane ring (8) having a twist-chair-boat ${ }^{15}$ (TCB) conformation. Superimposition ${ }^{25}$ of all the ring atoms of $\mathbf{2}$ on corresponding atoms in Density Functional Theory B3LYP/6-31g(d) ${ }^{26}$ calculated TCB conformation oxacyclononane (8) and cyclononane ${ }^{15}(\mathbf{9})$ models affords small root mean square (RMS) differences of only 0.168 and $0.109 \AA$ A., respectively [see comparison of torsion angles in Table 1]. Exchange of a methylene in model 9 into an ether oxygen in model 8 removes a transannular interaction between endo protons on $\mathrm{C}(2)$ and $\mathrm{C}(7)$, and as a result, brings the oxygen in $\mathbf{8}$ slightly closer to $\mathrm{C}(2)$ [2.838 $\AA$ and $2.992 \AA \mathrm{O} \cdots \mathrm{C}(7)$ in experimentally determined tagitinin A (7) and in calculated model-8, respectively versus $3.352 \AA \mathrm{C}(2) \cdots \mathrm{C}(7)$ in model-9]. The $14^{\circ} \mathrm{H}(6 \mathrm{a})-\mathrm{C}(6) \cdots \mathrm{C}(7)-\mathrm{H}(7 \mathrm{a})$ and $-3^{\circ} \mathrm{H}(3 \mathrm{a})-\mathrm{C}(3) \cdots \mathrm{C}(10)-$ $\mathrm{H}(10 \mathrm{a})$ torsion angles in $\mathbf{8}$ enable both a trans-6,7-lactone closure and 3,10-ethano bridging to proceed without strain. $O$-ethyl-tirotundin ${ }^{27}(\mathbf{1 0})$, a 1 -deoxy- $O(2)$-ethylated analogue of $\mathbf{2}$, has been isolated from $T$. rotundifolia. While coordinates of $\mathbf{1 0}$ are not to be found in the $\mathrm{CCDB}^{20}$ using Conquest $1.4,{ }^{28}$ nor in the article itself, ${ }^{27}$ endocyclic torsion angles for the nine-membered ring, the tetrahydrofuran ring, the lactone, as well as other selected torsion angles for 10, are available from Supplementary Material deposited for the paper. A comparison of these angles for $\mathbf{1 0}$ with those from $\mathbf{7}$ shows the same stereochemistry for both compounds (see Table 1). The root mean square (RMS) difference for the list of all 23 angles provided is only $3.0^{\circ}$. A subunit geometry comparison of $\mathbf{7}$ versus $\mathbf{1 0}$ affords RMS differences of $3.9^{\circ}$ for the endocyclic angles of the TCB conformation oxacyclononane moiety, $2.7^{\circ}$ for the 
tetrahydrofuran ring, and $2.2^{\circ}$ for the lactone. The iconic representation of $\mathbf{1 0}$ (as well as others to follow) is a 2Ddimensional projection of the actual 3D-dimensional structure. $^{29}$

Table 1. Selected torsion angles $\left[^{\circ}\right]$ measured for the X-ray crystallograhically determined molecular structures of tagitinin A $[(1 R, 3 R, 4 S, 6 R, 7 S, 8 R, 10 R)-7]$ and the 1 -deoxy- $O(2)$-ethylated analogue [ $(3 R, 4 S, 6 R, 7 S, 8 R, 10 S)-3$ - $O$-ethyl-tirotundin-10], versus corresponding angles in B3LYP calculated Twist-Chair-Boat (TCB) conformational models of oxacyclononane (8) and cyclononane (9)

\begin{tabular}{lrrrr}
\hline torsion angle & $\mathbf{7}$ & $\mathbf{1 0}^{a}$ & $\mathbf{8}$ & $\mathbf{9}$ \\
\hline $\mathrm{C}(10)-\mathrm{C}(1)-\mathrm{C}(2)-\mathrm{C}(3)$ & $-17.8(4)$ & -21.5 & & \\
$\mathrm{C}(10)-\mathrm{O}(1)-\mathrm{C}(3)-\mathrm{C}(2)$ & $21.3(3)$ & 17.8 & & \\
$\mathrm{C}(10)-\mathrm{O}(1)-\mathrm{C}(3)-\mathrm{C}(4)^{b}$ & $-101.8(3)$ & -104.4 & -80.4 & -70.5 \\
$\mathrm{C}(2)-\mathrm{C}(1)-\mathrm{C}(10)-\mathrm{C}(9)$ & $-89.3(3)$ & -85.6 & & \\
$\mathrm{C}(1)-\mathrm{C}(2)-\mathrm{C}(3)-\mathrm{C}(4)$ & $121.3(3)$ & 123.2 & & \\
$\mathrm{C}(1)-\mathrm{C}(2)-\mathrm{C}(3)-\mathrm{O}(1)$ & $-0.8(4)$ & -3.4 & & \\
$\mathrm{C}(2)-\mathrm{C}(3)-\mathrm{C}(4)-\mathrm{C}(5)$ & $-155.6(3)$ & -155.4 & & \\
$\mathrm{O}(1)-\mathrm{C}(3)-\mathrm{C}(4)-\mathrm{C}(5)^{b}$ & $-37.2(4)$ & -38.1 & -52.2 & -50.8 \\
$\mathrm{C}(3)-\mathrm{C}(4)-\mathrm{C}(5)-\mathrm{C}(6)$ & $92.0(4)$ & 95.1 & 91.0 & 103.0 \\
$\mathrm{C}(12)-\mathrm{O}(4)-\mathrm{C}(6)-\mathrm{C}(7)^{c}$ & $9.2(4)$ & 8.2 & & \\
$\mathrm{C}(6)-\mathrm{O}(4)-\mathrm{C}(12)-\mathrm{C}(11)^{c}$ & $-3.6(5)$ & -4.5 & & \\
$\mathrm{C}(4)-\mathrm{C}(5)-\mathrm{C}(6)-\mathrm{C}(7)$ & $-84.1(4)$ & -84.8 & -75.1 & -86.3 \\
$\mathrm{C}(5)-\mathrm{C}(6)-\mathrm{C}(7)-\mathrm{C}(8)$ & $105.6(3)$ & 107.4 & 106.2 & 103.0 \\
$\mathrm{O}(4)-\mathrm{C}(6)-\mathrm{C}(7)-\mathrm{C}(11)^{c}$ & $-10.6(3)$ & -8.3 & & \\
$\mathrm{C}(6)-\mathrm{C}(7)-\mathrm{C}(8)-\mathrm{C}(9)$ & $-56.4(4)$ & -64.0 & -57.6 & -51.0 \\
$\mathrm{C}(6)-\mathrm{C}(7)-\mathrm{C}(11)-\mathrm{C}(12)$ & $8.9(4)$ & 5.9 & & \\
$\mathrm{C}(7)-\mathrm{C}(8)-\mathrm{C}(9)-\mathrm{C}(10)$ & $-59.8(4)$ & -52.8 & -62.6 & -70.4 \\
$\mathrm{C}(8)-\mathrm{C}(9)-\mathrm{C}(10)-\mathrm{C}(1)$ & $173.8(3)$ & 173.4 & & \\
$\mathrm{C}(8)-\mathrm{C}(9)-\mathrm{C}(10)-\mathrm{O}(1)^{b}$ & $59.2(3)$ & 60.7 & 57.3 & 66.5 \\
$\mathrm{C}(7)-\mathrm{C}(11)-\mathrm{C}(12)-\mathrm{O}(4)^{c}$ & $-3.8(5)$ & -1.2 & & \\
$\mathrm{C}(13)-\mathrm{C}(11)-\mathrm{C}(12)-\mathrm{O}(5)$ & $-2.9(7)$ & & & \\
$\mathrm{H}(\mathrm{O} 2)-\mathrm{O}(2) \ldots \mathrm{C}(4)-\mathrm{H}(4)$ & $29(6)$ & & & \\
\hline
\end{tabular}

${ }^{a}$ Data taken from Supplementary Material deposited for ref. 27, $0.5^{\circ}$ average estimated deviation; ${ }^{b}$ Atom $\mathrm{O}(1)$ in $\mathbf{1 , 8 , 1 0}$ corresponds to atom $\mathrm{C}(1)$ in $\mathbf{9} ;{ }^{c}$ Atom $\mathrm{O}(4)$ in 7 corresponds to atom $\mathrm{O}(3)$ in $\mathbf{1 0 .}$

Anet has developed a very useful general analysis for subsequent assignment of substituent orientation (isoclinal, axial, equatorial) in rings of any size. ${ }^{30}$ Using this method, the $\mathrm{O}(3)$ hydroxyl, $\mathrm{C}(15)$ methyl, lactone $\mathrm{O}(4)$ and $\mathrm{C}(11)$ substituents can all be assigned equatorial descriptors, while the $\mathrm{O}(3)$ hydroxyl bonded to $\mathrm{C}(1)$ is pseudo-equatorial. In addition, the heterotopic $\mathrm{O}(2)$ and $\mathrm{C}(2)$ atoms ligated to $\mathrm{C}(3)$, the $\mathrm{C}(14)$ methyl and $\mathrm{C}(1)$ ligated to $\mathrm{C}(10)$, as well as the $\mathrm{H}(8)$ and oxycarbonyl $\mathrm{O}(6)$ bonded to $\mathrm{C}(8)$ can all be affixed "approximately" isoclinal descriptors. The tetrahydrofuranyl ring has an envelope conformation $\left[-0.8^{\circ} \mathrm{C}(1)-\mathrm{C}(2)-\mathrm{C}(3)-\mathrm{O}(1)\right.$ torsion angle] in which $\mathrm{C}(10)$ occupies the flap position.

Dale $^{31}$ has defined "corner" positions as medium ring atoms which have identically signed synclinal (gauche, ca. $60^{\circ}$ ) endocyclic torsion angles on either side. Since corner atoms have two isoclinal ligands pointing outwards, gem-dimethyl groups are commonly found at corner positions of medium rings. Ring atoms $\mathrm{C}(3)$ and $\mathrm{C}(10)$ in the TCB $C_{2}$-symmetry oxacyclononane and cyclononane models-8,9 are located at "corner" positions. Ligation of an ethano bridge to $\mathrm{C}(3,10)$ twists this region of the oxacyclononane ring in 7 , but $\mathrm{C}(3)$ and $\mathrm{C}(10)$ still retain their character as "corner-like" positions [torsion angles for $\mathrm{C}(3)$ are $37^{\circ}$ and $102^{\circ}$, while those on either side of $\mathrm{C}(10)$ are $-89^{\circ}$ and $-59^{\circ}$ ]. In accord with this, one finds the only two doubly-substituted oxacyclononane ring atoms in 7 to be $\mathrm{C}(3)$ [ligated to $\mathrm{O}(2)$ hydroxyl and ethano bridge $\mathrm{C}(2)$ ] and $\mathrm{C}(10)$ [ligated to $\mathrm{C}(14)$ methyl and ethano bridge $\mathrm{C}(1)]$. Ordinarily, substituents on these two close proximity doubly-substituted ring atoms $[\mathrm{C}(3,10)]$ would have suffered severe steric mutual repulsion, but this is removed in 7 by linking the two groups together as an ethano bridge. In the parent TCB $\mathrm{C}_{2}$-symmetry cyclononane conformation 9 it is apparent that $\mathrm{C}(8)$ is also a "corner" position, since it is homotopic to $\mathrm{C}(3)$. However, in the TCB conformation for the cis-fused tetrahydrofurano family of 3,10-epoxygermacrolide lactones it is unlikely that the $\mathrm{O}(6)$ oxycarbonyl $[-\mathrm{OC}(=\mathrm{O}) \mathrm{R}]$ moiety ligated to $\mathrm{C}(8)$ in 7 would have an $\alpha$-orientation (i.e. syn to the neighboring $\mathrm{C}(14)$ methyl). Such a disposition would afford an unfavorable 1,3-cis-diaxial type relationship. On the other hand, the $\mathrm{O}(6)$-oxycarbonyl moiety in the skew-chair-chair (SCC) conformation $3(2 \mathrm{H})$-furanone family of 3,10-epoxygermacrolide lactones can be either $\alpha^{-32-34}$ or $\beta-^{10-13,35-37}$ oriented since SCC represents a conformational change involving a flip of ring-atom $\mathrm{C}(9)$, and now the $\mathrm{C}(14)$ methyl is equatorial. Finally, one can predict that a epimeric C(15) methyl diastereomer of 7 would not be disposed to retain the TCB conformation since it would then suffer a transannular interaction with the inward pointing axial $\mathrm{H}(9 \beta)$.
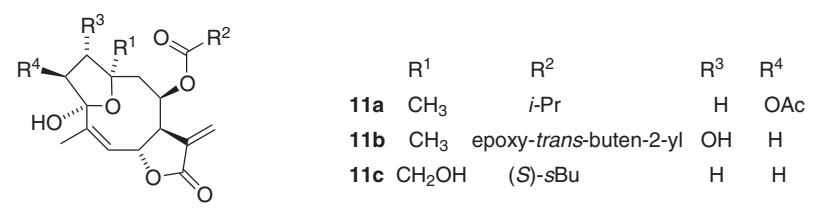

In addition to 10, the structures of woodhousin ${ }^{38}(\mathbf{1 1 a})$, niveusin C-2',3'-epoxide ${ }^{39}$ (11b) and tithonin ${ }^{40}$ (11c) are known from X-ray diffraction analysis. These three additional members of the CCDB cis-fused tetrahydrofurano family of 3,10-epoxy-germacrolide lactones contain a $\mathrm{C}(4,5)$ double-bond. A result of the endocyclic synperiplanar torsion angle in 11a-c is that the TCB conformation of $\mathbf{7 , 1 0}$ changes into a skew-chairboat type 3 (SCB type 3$)^{15}$ cis-cyclononene. The existence of cis-cyclononene conformational families has recently 
been discussed, e.g. SCB types 1-3 differ by having the double-bond located at different positions on the same SCB conformation ring. ${ }^{15}$

\section{Solution-state stereochemistry of tagitinin A}

The ${ }^{1} \mathrm{H}$ and ${ }^{13} \mathrm{C}$ NMR spectral parameters of crystalline 7 dissolved in acetone- $d 6$ are reported in Table 2. A fourteen-spin system is comprised of $\mathrm{H}(\mathrm{O} 2), \mathrm{H}(4 \beta), \mathrm{H}(5 \alpha)$, $\mathrm{H}(5 \beta), \mathrm{H}(6 \beta), \mathrm{H}(7 \alpha), \mathrm{H}(8 \alpha), \mathrm{H}(9 \alpha), \mathrm{H}(9 \beta), \mathrm{H}(13$ endo $)$, $\mathrm{H}(13$ exo $)$ and $\mathrm{C}(14) \underline{H}_{3}$. A four-spin system is composed of $\mathrm{H}(\mathrm{O} 3), \mathrm{H}(1 \alpha), \mathrm{H}(2 \alpha)$, and $\mathrm{H}(2 \beta)$, while a seven-spin system results from the isopropyl moiety. Homonuclear coupling pathways for each of these spin-systems were readily observed in the COSY-90 2D spectrum. The ${ }^{1} \mathrm{H}$ NMR spectrum $\left\{1.06 \mathrm{ppm}, \mathrm{C}(14) \underline{H}_{3}\right\}$ was simulated using $\mathrm{Gnmr}$ $4.1,{ }^{41}$ due to second order effects for signals arising from $\mathrm{H}(4 \beta, 5 \alpha)[\Delta v=15.5 \mathrm{~Hz}]$ and from $\mathrm{H}(9 \alpha, 9 \beta)[\Delta v=42.5 \mathrm{~Hz}]$. The multiplicity of protons ligated to ${ }^{13} \mathrm{C}$ nuclei was determined by DEPT-135 and DEPT-90 experiments. ${ }^{1} \mathrm{H}$ and ${ }^{13} \mathrm{C}$ signals were correlated using a 2D-NMR HETCOR spectrum. The $\mathrm{H}(13$ endo, $8 \alpha)$ signals overlap at $298^{\circ}$, but are readily differentiated by their coupling patterns. At $223^{\circ}, \mathrm{H}(13$ endo $)$ and $\mathrm{H}(8 \alpha)$ appear at $\delta 5.66$ and $\delta 5.55$, respectively. The resolution at low temperature was used to assign $\mathrm{H}(13$ endo, 13 exo $)$ by means of a NOESY spectrum measured at that temperature. In the $2 \mathrm{D}$ spectrum, $\mathrm{H}(8 \alpha)$ afforded a markedly higher intensity cross-peak to the 5.66 ppm olefinic proton relative to that observed for the 6.08 ppm geminal neighbor. Therefore, the $\delta 5.59$ and $\delta 6.10$ signals in the $298^{\circ}$ spectrum were assigned to $\mathrm{H}(13$ endo) [closer to $\mathrm{H}(8 \alpha)$ ] and $\mathrm{H}(13$ exo) [closer to lactone carbonyl $\mathrm{O}(5)]$, respectively.

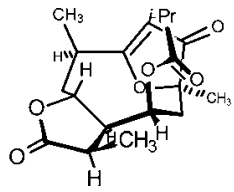

12

An important difference between the cis-fused tetrahydrofurano family of 3,10-epoxy-germacrolide lactones $(2,10,11 a-c)$ and the $3(2 \mathrm{H})$-furano-type [e.g. projection of the tetrahydrozexbrevin $\mathrm{A}$ (12) structure from $\mathrm{X}$-ray diffraction analysis $\left.{ }^{10}\right]$ is that the former set has the $\mathrm{C}(1)$ atom and $\mathrm{C}(8)$-oxycarbonyl moiety exhibiting diequatorial orientatons and ligated to a TCB [having a $\mathrm{C}(4)$ - $C(5)$ single bond] or SCB type 3 [having a $\mathrm{C}(4)=\mathrm{C}(5)$ double bond] nine-membered ring, while the latter family has them diaxially disposed and attached to a SCC conformation [with either $\mathrm{C}(4)-\mathrm{C}(5)$ single or double bonds]. This diaxial arrangement is found for other $3(2 \mathrm{H})$-furano-type 3,10-epoxy-germacrolides in the CCDB. ${ }^{10-13,35-37}$

Table 2. ${ }^{1} \mathrm{H}$ and ${ }^{13} \mathrm{C}$ NMR (acetone-d6) spectral parameters of tagitinin $\mathrm{A}, \mathbf{2}^{a}$

\begin{tabular}{|c|c|c|c|c|c|c|}
\hline & $\delta_{\mathrm{H}}$ & & $J_{\mathrm{HH}}$ & $\underline{H}-C-C-\underline{H}^{b}$ & & $\delta_{\mathrm{C}}$ \\
\hline $\mathrm{H}(1 \alpha)$ & $4.18[4.23]^{c}$ & $1 \alpha-2 \alpha$ & 9.3 & 21.5 & $\mathrm{C}(1)^{d}$ & $79.2[78.5]$ \\
\hline $\mathrm{H}(2 \alpha)$ & $2.35[2.44]^{c, e}$ & $1 \alpha-2 \beta$ & 7.2 & 141.0 & $\mathrm{C}(2)^{d}$ & 47.8 [46.9] \\
\hline $\mathrm{H}(2 \beta)$ & $2.05[2.1]^{c}$ & $1 \alpha-\mathrm{H}(\mathrm{O} 3)$ & 5.0 & . & $\mathrm{C}(3)^{d}$ & $106.4[105.7]$ \\
\hline $\mathrm{H}(4 \beta)$ & $2.169[2.1]^{c}$ & $2 \alpha-2 \beta$ & -13.7 & . & $\mathrm{C}(4)$ & $45.2[44.4]$ \\
\hline $\mathrm{H}(5 \alpha)$ & $2.138[2.1]^{c}$ & $4 \beta-5 \alpha$ & 8.1 & 147.2 & $\mathrm{C}(5)$ & $39.2[37.8]$ \\
\hline $\mathrm{H}(5 \beta)$ & $1.66[2.1]^{c}$ & $4 \beta-5 \beta$ & 0.0 & 96.6 & $C(6)$ & 82.2 [81.9] \\
\hline $\mathrm{H}(6 \beta)$ & $4.56[4.55]$ & $4 \beta-\mathrm{C}(15) \underline{\mathrm{H}}_{3}$ & $7.0[6.5]$ & . & $C(7)$ & $48.7[47.8]$ \\
\hline $\mathrm{H}(7 \alpha)$ & $4.05[3.99]^{c}$ & $4 \beta-\mathrm{H}(\mathrm{O} 2)$ & 1.0 & . & $\mathrm{C}(8)$ & $71.2[69.9]$ \\
\hline $\mathrm{H}(8 \alpha)$ & $5.59[5.59]$ & $5 \alpha-5 \beta$ & -13.2 & . & $\mathrm{C}(9)$ & $35.6[34.7]$ \\
\hline $\mathrm{H}(9 \alpha)$ & $1.911[1.95]^{e}$ & $5 \alpha-6 \beta$ & $10.9[9]$ & 161.7 & $\mathrm{C}(10)$ & $82.0[81.7]$ \\
\hline $\mathrm{H}(9 \beta)$ & $1.826[1.81]^{e}$ & $5 \beta-6 \beta$ & $1.3[3]$ & 82.1 & $\mathrm{C}(11)$ & 139.1 [137.0] \\
\hline $\mathrm{H}(13$ endo $)$ & $6.10[6.25]^{e}$ & $6 \beta-7 \alpha$ & $6.4[7]$ & 140.7 & $\mathrm{C}(12)$ & $169.4[169.8]$ \\
\hline $\mathrm{H}(13 \mathrm{exo})$ & $5.59[5.53]^{e}$ & $7 \alpha-8 \alpha$ & $3.1[1.5]$ & 56.7 & $\mathrm{C}(13)$ & $120.8[121.7]$ \\
\hline $\mathrm{C}(14) \underline{\mathrm{H}}_{3}$ & $1.35[1.43]^{f}$ & $7 \alpha-13$ endo & $3.3[3.5]^{e}$ & . & $\mathrm{C}(14)$ & $25.3[25.0]$ \\
\hline $\mathrm{C}(15) \underline{\mathrm{H}}_{3}$ & $1.06[1.11]$ & $7 \alpha-13$ ехо & $3.2[3]^{e}$ & . & $\mathrm{C}(15)^{g}$ & $19.0[19.2]$ \\
\hline $\mathrm{CH}\left(\mathrm{CH}_{3}\right)_{2}$ & $2.44[2.44]^{c}$ & $8 \alpha-9 \alpha$ & $5.3[5]^{e}$ & 58.9 & $\mathrm{C}(16)$ & $176.2[176.5]$ \\
\hline $\mathrm{CHC}_{3}$ & $1.03[1.07]$ & $8 \alpha-9 \beta$ & $11.7[8]^{e}$ & 175.1 & $\mathrm{C}(17)$ & $34.7[34.1]$ \\
\hline $\mathrm{CHC}_{3}{ }_{3}^{\prime}$ & $1.01[1.04]$ & $9 \alpha-9 \beta$ & $-14.3[13]$ & . & $\mathrm{C}(18)$ & $19.5[18.8]$ \\
\hline $\mathrm{H}(\mathrm{O} 2)$ & 4.77 & $\mathrm{CH}-\mathrm{CH}_{3}$ & $7.2[7]$ & . & $\mathrm{C}(19)^{g}$ & $19.0[18.4]$ \\
\hline $\mathrm{H}(\mathrm{O} 3)$ & 4.34 & $\mathrm{C} \underline{\mathrm{H}}-\mathrm{C} \underline{\mathrm{H}}_{3}{ }^{\prime}$ & $7.0[7]$ & . & & \\
\hline
\end{tabular}

${ }^{a}{ }^{1} \mathrm{H}$ NMR $(500 \mathrm{MHz}) ;{ }^{13} \mathrm{C}$ NMR $(125 \mathrm{MHz})$; chemical shifts relative to TMS (external), $298 \mathrm{~K}$, acetone- $d 6 ; \delta_{\mathrm{H}}$ and $J_{\mathrm{HH}}[\mathrm{Hz}]$ values from spectral simulation using Gnmr $4.1,{ }^{41}$ the standard deviation of the last digit in $J_{\mathrm{HH}}$ values is ca. $0.1 \mathrm{~Hz}$, values in square brackets from ref. 8 (measured in $\left.\mathrm{CDCl}_{3}\right) ;{ }^{b}$ Vicinal dihedral angle $\left[{ }^{\circ}\right]$ in X-ray crystallographic molecular structure $7 ;{ }^{c}$ Listed as a multiplet $(m)$ in ref. 8; ${ }^{d}$ Low intensity $\delta 79.11$, 47.88 shoulder, and 106.27 signals assigned to minor species respective $\mathrm{C}(1), \mathrm{C}(2)$, and $\mathrm{C}(3)$; major:minor ca. $3: 2$; ${ }^{e} \mathrm{Geminal}$ protons not differentially assigned in ref. $8 ;{ }^{f}$ Listed as 'broad' in ref. $8 ;{ }^{g}$ Two overlapping peaks at about double intensity. 
The magnitudes of the ${ }^{3} J(8 \alpha-9 \alpha)$ and ${ }^{3} J(8 \alpha-9 \beta)$ coupling constants are very characteristic of either TCB/ SCB type 3 or SCC 3,10-epoxy-germacrolide ninemembered ring conformations. X-ray diffraction analyses shows that dihedral angles $\mathrm{H}(8 \alpha)-\mathrm{C}(8)-\mathrm{C}(9)-\mathrm{H}(9 \alpha$, exo $)$ and $\mathrm{H}(8 \alpha)-\mathrm{C}(8)-\mathrm{C}(9)-\mathrm{H}(9 \beta$, endo) are respectively synclinal $\left[59^{\circ}\right]$ and antiperiplanar $\left[175^{\circ}\right]$ in TCB 7 , while both are synclinal in the SCC conformation [e.g. corresponding angles are $64^{\circ}$ and $53^{\circ}$, respectively in structure 12]. The ${ }^{3} J(8 \alpha-9 \alpha) 5.3 \mathrm{~Hz}$ and ${ }^{3} J(8 \alpha-9 \beta) 11.7$ values measured in the spectrum for an acetone- $d 6$ solution of crystalline $\mathbf{7}$ are consistent with a TCB conformational bias for the $\mathrm{C}(8)-\mathrm{C}(10)$ fragment in this medium. Unequal magnitude coupling constants are also found in SCB type 3 conformation nine-membered rings which differ from those of the TCB type in that the $\mathrm{C}(4)-\mathrm{C}(5)$ single bond has been replaced by a $\mathrm{C}(4)=\mathrm{C}(5)$ double-bond. For example, the ${ }^{3} J(8 \alpha-9 \alpha)$ and ${ }^{3} J(8 \alpha-9 \beta)$ coupling constants for niveusin C-2'3'-epoxide (11b, which has a $1 \alpha$-hydroxyl cis-tetrahydrofurano moiety) are respectively 6.8 and 9.5 $\mathrm{Hz} .{ }^{39}$ For 1,2-dehydroniveusin C-2'3'-epoxide, a 1,2dehydrofurano analogue of $\mathbf{1 1 b}$, both values are reported to be $3.5 \mathrm{~Hz} .^{39}$ This is in accord with a conformational change from what is now known as a SCB type 3 for $\mathbf{1 1 b}$ to a SCC conformation where both ${ }^{3} J(8 \alpha-9 \alpha)$ and ${ }^{3} J(8 \alpha-9 \beta)$ coupling constants are expected to have similar synclinal magnitudes.

Irradiation of $\mathrm{H}(9 \beta)\{\delta 1.83\}$ afforded a $4.2 \%$ nuclear Overhauser effect intensity enhancement to $\mathrm{H}(6 \beta)$ and a $3.2 \%$ NOE effect for the signal at $\delta 2.16$ [overlapping $\delta 2.17$ $\mathrm{H}(4 \beta)$ and $\delta 2.14 \mathrm{H}(5 \alpha)]$. Similarly, $\{\delta 2.16\}$ gave $7.8 \%$ and $4.7 \%$ NOE effects to the respective $\mathrm{H}(6 \beta)$ and $\mathrm{H}(9 \beta)$ resonances. Finally, an $1.8 \%$ NOE to $\mathrm{H}(9 \beta)$ and a $2.3 \%$ NOE to the overlapping $\delta 2.17 \mathrm{H}(4 \beta)$ and $\delta 2.14 \mathrm{H}(5 \alpha)$ multiplets were measured upon $\{\delta 4.56, \mathrm{H}(6 \beta)\}$. These NOE results are all consistent with a TCB conformation in which $\mathrm{H}(9 \beta)$ is pointing into the interior towards its transannular $\mathrm{H}(4 \beta)$ and $\mathrm{H}(6 \beta)$ neighbors, while it would be pointing away from these protons in the SCC conformation.

For the $\mathrm{C}(3)-\mathrm{C}(6)$ fragment, the measured $8.1 \mathrm{~Hz}^{3} J(4 \beta-$ $5 \alpha)$ and $c a .0 \mathrm{~Hz}^{3} J(4 \beta-5 \beta)$ values are also consistent with a TCB conformation and not those expected for the SCB. The dihedral angles $\mathrm{H}(4 \beta)-\mathrm{C}(4)-\mathrm{C}(5)-\mathrm{H}(5 \alpha)$ and $\mathrm{H}(4 \beta)-$ $\mathrm{C}(4)-\mathrm{C}(5)-\mathrm{H}(5 \beta)$ are respectively, $147^{\circ}$ and $97^{\circ}$ in structure 7. Therefore, the vicinal proton-proton coupling constants and NOE experiments are all consistent with an acetone-d6 solution-state nine-membered ring conformation that is similar to the TCB found for crystalline 7. However, inspection of the ${ }^{13} \mathrm{C}$ NMR and DEPT spectra shows the presence of low intensity $\delta 79.1,47.9$ (shoulder), and 106.3 methine signals that are $c a$. $0.1 \mathrm{ppm}$ from methine resonances assigned to the respective $\mathrm{C}(1), \mathrm{C}(2)$, and $\mathrm{C}(3)$ [major:minor ca. 3:2]. Low intensity ${ }^{13} \mathrm{C}$ NMR signals were not observed from other carbon nuclei in the molecule. Thus, while the nine-membered ring TCB conformation appears to be population biased, some small degree of flexibility appears to exist for the tetrahydrofuran moiety of tagitinin A in solution. The lower magnitudes of the minor component peak intensities are consistent with a slow exchange partner(s) either having a different puckering of the THFmoiety, or involving different rotamers about the $\mathrm{C}(3)$ $\mathrm{O}(2)$ bond. In this regard, it is noted that a $1.0 \mathrm{~Hz}$ long-range ${ }^{4} J(4 \beta-\mathrm{H}(\mathrm{O} 2))$ coupling is apparent from the $\mathrm{H}(\mathrm{O} 2)$ doublet which transformed into singlet multiplicity upon homonuclear decoupling $\{2.17 \mathrm{ppm}, \mathrm{H}(4 \beta)\}$. Similarly, the broadened signals for $\mathrm{H}(4 \beta)$ sharpened upon $\{4.77 \mathrm{ppm}$, $\mathrm{H}(\mathrm{O} 2)\}$. Variable temperature experiments [from 313 to 223 $\mathrm{K}$ ] were then undertaken to search for a slow exchange partner in the ${ }^{1} \mathrm{H}$ NMR spectrum, but none was observed.

Nine-membered ring conformational interconversion and molecular modeling

Medium rings are large enough to undergo conformational interchange by segmental motion. ${ }^{15}$ One of the mechanisms for medium ring conformational interchange is the ring atom-flip ${ }^{42}$ (also referred to as "wagging") ${ }^{43}$ In this interconversion, one of the ring atoms flips to the other side of the ring, and in so doing, the axial and equatorial disposition of its exocyclic ligands are interchanged. This exchange of axial/equatorial orientations also occurs to exocyclic ligands on ring-atoms located at either side of the flipping atom. ${ }^{15}$ Thus, $\mathrm{H}(8 \mathrm{a})$ is equatorial in SCB type 3 (13) and axially oriented in SCC (14) B3LYP/6-31g(d) models of cyclononene. ${ }^{15}$ Flipped ring-atoms conformations have been observed by X-ray diffraction analysis: two ring atom-flipped eight-membered ring conformations superimpose upon each other in conformationally dynamically disordered crystals of nefopam methobromide or methiodide quaternary ammonium salts. ${ }^{44,45}$

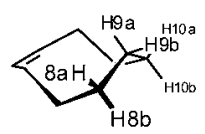

13

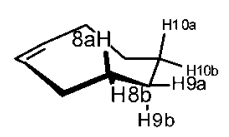

14
The above stereochemical analysis can be combined with an earlier observation by Gershenzon et al. ${ }^{39}$ who isolated 11b (a 1 $\alpha$-hydroxyl cis-tetrahydrofurano analogue) and the corresponding 1,2-dehydrofurano germacrolide lactone from the Viguiera microphylla plant. The authors 
noted that there were significant differences in the chemical shifts and coupling constants of the $\mathrm{H}(6,7,8,9 \alpha, 9 \beta)$ protons measured in their 1H NMR spectra [ $\operatorname{see}^{3} J(8 \alpha-9 \alpha)$ and ${ }^{3} J(8 \alpha-$ $9 \beta$ ) values for $\mathbf{1 1 b}$ noted above]. ${ }^{39}$ These were attributed to the presence of a $1 \alpha$-hydroxyl group or a 1,2-double bond, and also to conformational differences involving the orientation of the $8 \beta$-oxycarbonyl moiety. "The side chain appears to have an equatorial orientation in the $1 \alpha$-hydroxyl compounds and an axial orientation in the $\Delta^{1(2)}$ compounds. ${ }^{39}$ We note that the hybridization of $\mathrm{C}(1)$ seems to be at the root for $(\mathrm{T} / \mathrm{S}) \mathrm{CB}$ versus SCC conformational preference, and subsequent diequatorial or diaxial disposition for the $\mathrm{C}(1)$ atom/ $8 \beta$-oxycarbonyl moiety. As an input structure for DFT B3LYP/6-31g(d) modeling, the 11c skeleton was converted into a $3(2 \mathrm{H})$ furanone having an $8 \beta$-oxyformyl group for simplicity. A trigonal $\mathrm{C}(1)$ atom appears to be essential for an SCC conformational preference with an axially oriented C(1), while a tetrahedral C(1) affords a preferred SCB type 3 with an equatorial C(1). The $3(2 \mathrm{H})$ furanone SCB type 3 conformational model (15) was found to be $0.87 \mathrm{kcal}$ higher in energy than the SCC model (16). Keeping the $\mathrm{C}(1)$ carbonyl intact while changing the $\mathrm{C}(2)=\mathrm{C}(3)$ double bond to a single bond still afforded an SCB type 3 model (17) that was higher in energy [1.70 kcal] versus the SCC 2,3-dihydrofuranone model (18). However, when the trigonal $\mathrm{C}(1)$ carbonyl was changed to a tetrahedraltype methylene carbon, while now keeping the $C(2)=C(3)$ double bond, the SCC conformation (model 19) then became higher $[2.60 \mathrm{kcal}]$ relative to that for the SCB type 3 diastereomer (model 20).

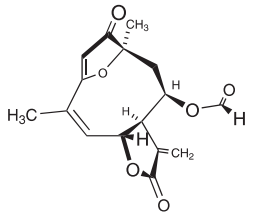

15

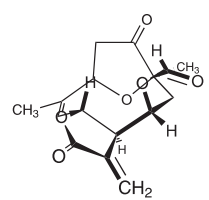

18

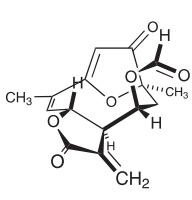

16

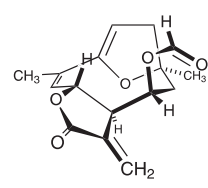

19

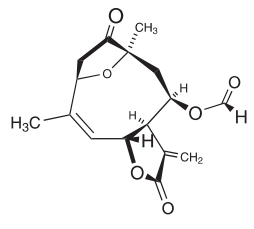

17

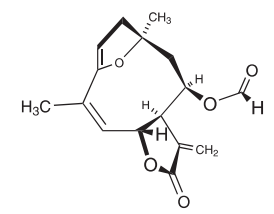

20
Finally, the observation of a ${ }^{4} J(4 \beta-\mathrm{H}(\mathrm{O} 2)) 1.0 \mathrm{~Hz}$ longrange coupling constant for the $\mathrm{H}(\mathrm{O} 2)$ doublet can be rationalized if there is a solution-state conformational bias for the same coplanar "W-type" geometry involving the $\mathrm{H}(\mathrm{O} 2), \mathrm{O}(2), \mathrm{C}(3), \mathrm{C}(4)$, and $\mathrm{H}(4 \beta)$ atoms as found in crystalline state 7 [with a $29(6)^{\circ}$ approximate synperiplanar $\mathrm{H}(\mathrm{O} 2)-\mathrm{O}(2) \cdots \mathrm{C}(4)-\mathrm{H}(4 \beta)$ torsion angle], where $\mathrm{H}(\mathrm{O} 2)$ is hydrogen-bound to the 8-oxycarbonyl oxygen $\mathrm{O}(7 \mathrm{a})$ of an adjacent symmetry equivalent molecule.

In conclusion, as with 8-desmethylacrylhexahydroxyzexbrevin (3), Horeau's rule also failed to predict the correct $\alpha / \beta$-relative configuration for the 1-hydroxyl group in tagitinin $\mathrm{A}$, and its configuration at $\mathrm{C}(1)$ must now be reassigned as $1 \beta$. Analysis of the ${ }^{1} \mathrm{H}$ NMR spectrum of $\mathbf{2}$ shows tagitinin A to maintain its crystallographically found TCB conformation and "W-like" $\mathrm{H}(\mathrm{O} 2)-\mathrm{O}(2)-\mathrm{C}(3)-\mathrm{C}(4)-\mathrm{H}(4 \beta)$ arrangement in acetone- $d 6$ solution. Finally, the TCB/SCB type 3 conformations of the saturated/unsaturated ninemembered moieties within 3,10-epoxy-germacrolide rings can be interconverted to SCC by means of a $\mathrm{C}(9)$ ring atom-flip mechanism which changes the orientation of the $\mathrm{C}(1)$ atom and $\mathrm{C}(8)$-oxycarbonyl moiety from diequatorial to diaxial. The stereochemistry of 3,10-epoxygermacrolide lactone structures in the CCDB, and the DFT $\mathrm{B} 3 \mathrm{LYP} / 6-31 \mathrm{~g}(\mathrm{~d})$ modeling results in this work can be interpreted as showing that tetrahedral $\mathrm{C}(1)$ atoms stabilize the TCB/SCB type 3 conformations, while their trigonal counterparts stabilize the SCC conformation.

\section{Experimental}

\section{Isolation of tagitinin A (2)}

Dried aerial parts $(1 \mathrm{~kg})$ of Tithonia diversifolia (Hemsl.) A. Gray (collected in San Blas, Nayarit, México, on December 2001, voucher deposited in the National Herbarium, Instituto de Biología de la UNAM, registry number: MEXU-1014633) were extracted successively with hexane and dichloromethane. The dichloromethane extract was concentrated in-vacuo to give a dark-green residue $(30 \mathrm{~g})$, which was separated on a silica gel 60 column (260 g, fractions of $250 \mathrm{~mL}$ were collected). Hexane was used as the initial mobile phase, and was followed by hexane-ethyl acetate mixtures (95:5, 9:1, 4:1, 7:3, 3:2, $1: 1)$. The residue $(4.2 \mathrm{~g})$ from the fractions eluted with a $1: 1$ solvent mixture was subjected again to silica gel 60 column chromatography (18 g) eluted with dichloromethane-acetone. Fractions eluted with dichloromethane-acetone (9:1) gave a white amorphous solid, which was crystallized from ethyl acetate-isopropyl ether, and then recrystallized from methanol to afford 2 [85 mg, mp 172-174 ${ }^{\circ} \mathrm{C}$ (lit. $\left.{ }^{8} 170{ }^{\circ} \mathrm{C}\right)$ ].

\section{Molecular modeling and graphics}

Density Functional Theory B3LYP/6-31g(d) geometry optimized models $\mathbf{8 , 9}, \mathbf{1 3 - 2 0}$ were produced with the Gaussian-98W revision A-7 program, ${ }^{26}$ and all were found 
to have only positive values for vibrational frequencies. Superimposition of molecular structures was performed with the MacMimic 3.0 program. ${ }^{25}$ Ball and stick-type noniconic molecular graphics were drawn with the Ball\&Stick $3.8 \beta 3$ program. ${ }^{19} 2 \mathrm{D}$-iconic projections of the molecular models and X-ray crystallographic 3D-structures were generated using the combination of CS-Chem 3 D Pro 5.0 and CS-ChemDraw Ultra 5.0 programs. ${ }^{29}$

\section{NMR Spectroscopy}

${ }^{1} \mathrm{H}$ and ${ }^{13} \mathrm{C}$ NMR spectroscopy were recorded at 500 and $125 \mathrm{MHz}$, respectively, at $298 \mathrm{~K}$ on a Varian Unity-Plus500 NMR spectrometer. Samples were measured in acetone- $d 6$ using the deuterio solvent as an internal lock, and tetramethylsilane (TMS) as the internal spectral reference. DEPT $\left(90^{\circ}\right.$ and $135^{\circ}$ pulse angles) were used to determine the hydrogen multiplicity of the ${ }^{13} \mathrm{C}$ signals. COSY 2D NMR spectroscopy was used to ascertain the spin-spin coupling systems, and HETCOR 2D-NMR spectroscopy was used to correlate the ${ }^{13} \mathrm{C}$ and ${ }^{1} \mathrm{H}$ chemical shifts. NOE experiments were performed using the NOE-Difference technique, as well as by a NOESY $2 \mathrm{D}$ spectrum. ${ }^{1} \mathrm{H}$ spectral simulation was performed using the Gnmr 4.1 program. ${ }^{41}$

\section{Crystallography}

Crystallographic measurements were made on a Bruker Smart Apex automatic diffractometer with a CCD area detector using graphite-monochromated Mo $\mathrm{K} \alpha(\lambda=$ $0.71073 \AA$ ) radiation. A clear, colorless plate crystal of $\mathrm{C}_{19} \mathrm{H}_{28} \mathrm{O}_{7}, 2$, [grown by slow crystallization from methanol] having approximate dimensions $0.40 \times 0.20 \times 0.18 \mathrm{~mm}$ was chosen, mounted on glass fiber, fixed on a goniometer head, and then placed in the X-ray diffractometer. The SMART 5.625 program $^{46}$ was used for centering, indexing, and data collection. Unit cell dimensions were obtained by a leastsquares fit of 3439 carefully centered reflections in the range of $2.27^{\circ} \mathrm{d} \theta \mathrm{d} 30.94^{\circ}$. Cell constants correspond to an orthorhombic system $P 22_{1} 2_{1}$ cell with dimensions at 291(2) K of: $a=9.6580(13) \AA, b=9.9775(13) \AA, c=20.360(3) \AA, V$ $=1961.9(5) \AA^{3}$. For $Z=4$ and $\mathrm{FW}=368.41$, the calculated density is $1.247 \mathrm{~g} \mathrm{~cm}^{-3}$. Data were collected at 291(2) $\mathrm{K}$ using the $\omega$ scan technique. Space group determination was based upon systematic absences, packing considerations, a statistical analysis of intensity distribution, and the successful solution and refinement of the structure. Data were collected to a maximum $\theta$ value of $24.99^{\circ}(100 \%$ completeness to $\theta$ ) and no significant decay was observed.

The structure was solved by direct methods and refined by full matrix least squares on $F^{2}$ using the SHELXTL97 program. ${ }^{47}$ Atomic scattering factors were taken from
Volume IV of the International Tables for X-ray Crystallography. ${ }^{48}$ Non-hydrogen atoms were refined anisotropically, while hydrogens were placed at calculated positions, and refined as riding atoms on their respective attached atom, with the exception of those ligated to $\mathrm{O}(2)$ and $\mathrm{O}(3)$ which were located and refined as non-hydrogen atoms with a $U 1.2 \AA^{2}$ thermal isotropic factor from the attached $\mathrm{O}$-atom. At convergence, the final discrepancy indices on $F$ were $R(F)=0.0523, R_{\mathrm{w}}\left(F^{2}\right)=0.0990$ and GOF on $F^{2}=0.902$ for the 3459 reflections with $I_{\text {net }}$ t $2 \sigma\left(I_{\text {net }}\right)$ and 245 parameters refined with 0 restraints and 0 constraints. The largest difference peak and hole was 0.149 and -0.130 e. $\AA^{-3}$.

\section{Acknowledgements}

The authors thank M. Sc. Simón Hernández-Ortega (Instituto de Química de la UNAM) for technical assistance. Partial financial support by Consejo Nacional de Ciencia y Tecnología through a scholarship for A. G. (register: 159657), and by DGAPA-UNAM (grant IN233202) is gratefully acknowledged. Travel funds to Mexico were provided to R.G. by BGUN.

\section{Electronic Supplementary Information}

Crystallographic data have been deposited with the Cambridge Crystallographic Data Centre as supplementary publication no. CCDC 261295. Copies of the material can be obtained, free of charge via www.ccdc.cam.ac.uk/conts/ retrieving.html (or from the Cambridge Crystallographic Data Centre, CCDC, 12 Union Road, Cambridge, CB2 1EZ UK; Tel: +44 1223 336408; Fax: +44 1223 336033; or email: deposit@ccdc.cam.ac.uk).

\section{References}

1. Horeau, A.; Tetrahedron Lett. 1961, 506; ibid. 1962, 965; Horeau, A.; Kagan, H. B.; Tetrahedron 1964, 20, 2431.

2. Eliel, E. L.; Wilen, S. H.; Mander, L. N.; Stereochemistry of Organic Compounds, Wiley-Interscience: New York, 1994, p. 140-142.

3. Brewster, J. H. In Elucidation of Organic Structures by Physical and Chemical Methods; Bentley, K. W.; Kirby, G. W., eds.; $2^{\text {nd }}$ ed., Wiley-Interscience: New York, 1972, p. 1-249, vol. IV, Part III.

4. Horeau, A.; Stereochemistry, Fundamentals and Methods, Georg Thieme Publishers: Stuttgart, 1977, vol 3.

5. Kupchan, S. M.; Kelsey, J. E.; Sim, G. A.; Tetrahedron Lett. 1967, 2863.

6. Rogers, D.; Moss, G. P.; Neidle, S.; J. Chem. Soc. Chem. Commun. 1972, 142. 
7. Romo de Vivar, A.; Guerrero, C.; Díaz, E.; Ortega, A.; Tetrahedron 1970, 26, 1657; It has been suggested that the actual natural source of Zexbrevin is Viguiera greggi: Delgado, G.; Alvarez, L.; Mata, R.; Pereda-Miranda, R.; Romo de Vivar, A.; Villaseñor, J. L.; J. Nat. Prod. 1986, 49, 1165; Romo de Vivar, A.; Delgado, G.; Bol. Soc. Chil. Quím. 1985, 30, 79.

8. Baruah, N. C.; Sharma, R. P.; Madhusudanan, K. P.; Thyagrarajan, G.; Herz. W.; Murari, R.; J. Org. Chem. 1979, 44, 1831; Sarma, J. C.; Sharma, R. P.; de Jong, R.; Stam, C. H.; Phytochemistry 1987, 26, 2406.

9. Fischer, N. H.; Oliver, E. J.; Fischer, H. D.; Prog. Chem. Org. Nat. Prod. 1979, 38, 47.

10. Soriano-García, M.; Toscano, R. A.; Acta Crystallogr. 1984, C40, 1425.

11. Fronzek, F. R.; Lee, I-Y.; Fischer, N. H.; J. Nat. Prod. 1983, 46, 104.

12. Rodríguez-Hahn, L.; Jiménez, M.; Saucedo, R.; SorianoGarcía, M.; Toscano, R. A.; Díaz, E.; Tetrahedron 1983, 39, 3909.

13. Soriano-García, M.; Toscano, R. A.; Díaz, E.; Rodríguez-Hahn, L.; Rev. Latinoamer. Quím. 1985, 16, 112.

14. Pal, R.; Kulshreshta, D. K.; Rastogi, R. P.; Indian J. Chem. 1976, 14B, 77 and 259; ibid. 1977, 15B, 208 and 533. For additional studies on Tithonia diversifolia, see: Pereira, P. S.; Dias, D. A.; Vichnewski, W.; Turco Tussi Nasi, A. M.; Herz, W.; Phytochemistry 1997, 45, 1445; Kuo, Y.-H.; Chen, Ch.H.; J. Nat. Prod. 1998, 61, 827; Gu, J.-Q.; Gills, J.J.; Park, E. J.; Mata-Greenwood, E.; Hawthorne, M. E.; Axelrod, F.; Chavez, P. I.; Fong, H. H. S.; Mehta, R. G.; Pezzuto, J. M.; Kinghorn, A. D.; J. Nat. Prod. 2002, 65, 532.

15. Glaser, R.; Shiftan, D.; Levi-Roso, G.; Ergaz, I.; Geresh, S.; J. Org. Chem. 2002, 67, 5486.

16. Heinrich, M.; Robles, M.; West, J. A.; Ortíz de Montellano, B. R.; Rodríguez, E.; Annu. Rev. Pharmacol. Toxicol. 1998, 38, 539.

17. Bijvoet, J. M.; Peerdeman, A. F.; van Brommel, A. J.; Nature (London) 1951, 168, 271.

18. The authors have deposited atomic coordinates for $\mathbf{2}$ with the Cambridge Crystallographic Data Centre. The coordinates can be obtained, free of charge via www.ccdc.cam.ac.uk/conts/ retrieving.html (or from the Cambridge Crystallographic Data Centre, CCDC, 12 Union Road, Cambridge, CB2 1EZ UK; Tel: +44 1223 336408; Fax: +44 1223 336033; or e-mail: deposit@ccdc.cam.ac.uk).

19. Müller, N.; Ball\&Stick 3.8ק3, Institut für Chemie, Johannes Kepler Universität: Linz, Austria, 2000.

20. Allen, F. H. ; Acta Crystallogr. 2002, B58, 380.

21. González, A. G.; Galindo, H.; Mansilla, H.; Kestermich, V. H. ; Palenzuela, J. A.; Rodríguez, M. L.; J. Nat. Prod. 1990, 53, 462.

22. Macias, F. A.; Aguilar, J. M.; Molinillo, J. M. G.; Massanet, G. M. Fronczek, F. R.; Tetrahedron 1994, 50, 5439.

23. Quijano, L.; Núñez, I. S.; Fronczek, F. R.; Fischer, N. H.; Phytochemistry 1997, 45, 769.
24. Hayashi, T.; Nakano, T.; Kozuka, M.; McPhail, D. R.; McPhail, A. T.; Lee, K. H.; J. Nat. Prod. 1999, 62, 302.

25. Sundin, A.; MacMimic 3.0, In-Star Software: Lund, Sweden, 1996 [now Department of Bioorganic Chemistry, Lund Technische Hochsuhle: Lund, Sweden].

26. Gaussian-98W, revision A-7; Gaussian Inc.: Pittsburgh, PA, 1998.

27. Herz, W.; Blount, J. F.; J. Org. Chem. 1978, 43, 1268.

28. Bruno, I. J.; Cole, J. C.; Edgington, P. R.; Kessler, M.; Macrae, C. F.; McCabe, P.; Pearson, J.; Taylor, R.; Acta Crystallogr. 2002, B58, 389.

29. CSChemDraw Ultra 5.0; CambridgeSoft: Cambridge, MA, 1999; Chem3D Pro 5.0; CambridgeSoft: Cambridge, MA, 1999.

30. Anet, F. A. L.; Tetrahedron Lett. 1990, 31, 2125.

31. Dale, J.; Stereochemistry and Conformational Analysis, Universitetsforlaget/Verlag Chemie: Oslo/New York, 1978, p. 206.

32. Herz, W.; Goedken, V. L.; J. Org. Chem. 1982, 47, 2798.

33. Le Quesne, P. W.; Menachery, M. D.; Pastore, M. P.; Kelley, C. J.; Brennan, T. F.; Onan, K. D.; Raffauf, R. F.; Weeks, C. M.; J. Org. Chem. 1982, 47, 1519.

34. Manchand, P. S.; Todaro, L. J.; Cordell, G. A.; Soejarto, D. D.; J. Org. Chem. 1983, 48, 4388.

35. Lee, I.-Y.; Fronczek, F. R.; Malcolm, A.; Fischer, N. H.; Urbatsch, L. E.; J. Nat. Prod. 1982, 45, 311.

36. Fischer, N. H.; Lee, I.-Y.; Fronczek, F. R.; Chiari, G.; Urbatsch, L. E.; J. Nat. Prod. 1984, 47, 419.

37. Castañeda-Acosta, J.; Ober, A. G.; Fronczek, F. R.; Fischer, N. H.; Chiari, G.; J. Chem. Cryst. 1997, 27, 641.

38. Herz, W.; Blount, J. F.; J. Org. Chem. 1978, 43, 4887.

39. Gershenzon, J.; Liu, Y.-L.; Mabry, T. J.; Korp, J. D.; Bernal, I.; Phytochemistry 1984, 23, 1281.

40. Rodríguez, J. D.; Perales, A.; Rodríguez-Ubis, J. C.; Vázquez, P.; Borges, J.; J. Nat. Prod. 1995, 58, 446.

41. Budzelaar, P. H. M.; Gnmr 4.1; Cherwell Scientific Ltd.: Oxford, U.K., 1999.

42. Goto, H.; Osawa, E.; J. Am. Chem. Soc. 1989, 111, 8950.

43. Hendrickson, J. B.; J. Am. Chem. Soc. 1967, 89, 7047.

44. Glaser, R.; Michel, A.; Drouin, M.; Can. J. Chem. 1990, 68, 1128.

45. Glaser, R.; Novoselsky, A.; Shiftan, D.; Drouin, M.; J. Org. Chem. 2000, 65, 6345.

46. SMART (5.625); Bruker AXS Inc.: Madison, WI, 2000.

47. Sheldrick, G. M.; SHELXTL97; An Integrated System for Solving, Refining and Displaying Crystal Structures from Diffraction Data, University of Göttingen: Germany, 1997.

48. International Tables for X-ray Crystallography, Kynoch Press: Birmingham, vol IV, 1974.

Received: November 28, 2004 Published on the web: April 12, 2005 